\title{
Acerca de las expectativas musicales en la actualidad
}

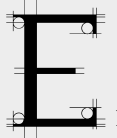

$\mathrm{n}$ el mundo actual, el avance de la tecnología (Internet, redes sociales, etcétera), la saturación de opciones convencionales de trabajo, la recesión económica mundial en la que se vive, y otros factores, influyen directa o indirectamente en las disciplinas artísticas, así como en sus exponentes. En las últimas décadas, las formas convencionales de concebir el arte como medio para obtener satisfactores propios del ser humano (emocionales, económicos, psicológicos, etcétera) se han venido transformando y en algunos casos han desaparecido casi por completo. De manera particular, en el área de la música, la imagen del solista virtuoso del siglo XIX, el compositor incomprendido por la sociedad, el músico académico gran vendedor de discos, etcétera, si bien no han desaparecido del todo, ha sufrido cambios significativos.

La guitarra acústica, por ejemplo, ya sea por su fuerte arraigo en la música popular o por sus limitaciones técnicas en cuanto a la proyección de volumen, repertorio, o por el hecho de que es un instrumento relativamente "nuevo" -en comparación con el violín o el piano- le ofrece una gran variedad de opciones laborales al guitarrista contemporáneo, pero a la vez lo limita.

Por ejemplo, las figuras emblemáticas de Andrés Segovia, Julian Bream y John Williams que en buena medida y durante mucho tiempo han sido factores de motivación para incipientes estudiantes de guitarra, poco o nada podrían servir en la actualidad, ya que ellos definieron y promovieron el repertorio de la guitarra como instrumento de concierto y, en el caso de Segovia, la técnica, por lo que el guitarrista contemporáneo debe incursionar en el medio con estrategias frescas, puesto que, de lo contrario, sería como tratar de hacerse famoso inventando algo que ya ha sido inventado mucho tiempo atrás. Incluso en el ámbito de la música pop, interpretaciones de Jimmy Page, Eric Clapton, Jimmy Hendrix o de agrupaciones como Led Zeppelin, Pink Floyd o, en los últimos años, de Metallica y Guns N' Roses, por citar algunos grandes fenómenos de ventas que han influido a guitarristas de la música pop, siguen estando vigentes, pero no ocurre lo mismo con los modelos y fórmulas de marketing y producción que los hicieron exitosos.

El guitarrista John Williams, como otros intérpretes del ámbito musical académico, formó a finales de la década de 1970 el grupo Sky, con el cual realizó giras y conciertos en el segmento del rock-clásico. Su álbum debut, llamado simplemente $S k y$, fue un gran éxito en Reino Unido y Australia. El siguiente trabajo fue un doble álbum, Sky 2, que obtuvo un mayor éxito, llegando a ser uno de los discos más vendidos 
del año de 1980. Julian Bream, por ejemplo, formó la agrupación Julian Bream Consort, un ensamble instrumental de época, donde él mismo tocaba el laúd, y despertó el interés en la música de la época isabelina, grabó discos y ofreció conciertos en giras a lo largo de todo el mundo. Las motivaciones de estos dos intérpretes quizás no fueron del todo económicas ni nuevas, pero nos dan una idea del campo laboral del guitarrista contemporáneo.

En el ámbito de la música popular-comercial, las ventas de discos y los conciertos también han sufrido cambios significativos. Valiéndose en gran parte de la tecnología, los artistas de música popular llegan a un público más numeroso y pueden continuar vigentes. La compra y venta de discos se realiza a través de Internet por medio de los formatos digitales, en tiendas como iTunes o en la página web del artista; el usuario puede comprar con tarjeta de crédito las canciones que él seleccione sin necesidad de comprar todo el disco. Asimismo, en establecimientos como Starbucks se ofrece la venta de música. Recientemente, los Rolling Stones sacaron a la venta una recopilación de cuarenta de sus éxitos en una memory flash. La llegada del DVD y, recientemente, del Blu-ray ofrecen privilegios especiales como descargas "exclusivas". En cuanto a los conciertos, la manera tradicional de ver al artista sólo para escuchar sus éxitos ha derivado en grandes espectáculos de multimedia, en algunas ocasiones con abuso de la tecnología, en donde lo visual es igual o más importante que lo musical, un ejemplo de esto son las presentaciones de la cantante Madonna.

Factores como los anteriormente señalados reinventan la relación intérprete-público, ya sea en el ámbito académico, como las puestas en escena de óperas del repertorio consagrado del bel canto, con vestuario y escenografías modernas e incluso en ocasiones con la participación directa del público. En el ámbito pop, agrupaciones nuevas han logrado hacer carrera a través de MySpace, Facebook y YouTube, rompiendo así los esquemas impuestos por el mainstream. Es por ello que los medios, para poder ingresar al vasto ambiente musical actual, tienen que ser modificados, no sólo en el campo de la música académica, con ensambles novedosos, sino también en el campo de la música nueva o en la música popularcomercial, realizando la promoción a través de las redes sociales. La gama de opciones para poder ingresar al vasto ambiente musical es amplia, puede ser como músico de estudio, musicalizando spots de radio y televisión, en el ámbito pedagógico (instrucción musical en línea), etcétera. Por ejemplo, el guitarrista mexicano José Luis Navarro propone la enseñanza de la guitarra clásica a través de herramientas de Internet, como YouTube, Messenger, entre otras, lo cual es un medio alternativo en el campo laboral.

El quinteto de metales M5, que realizó una residencia en el Conservatorio de las Rosas en el periodo 2008-2011, ofrece una propuesta "nueva" mediante los "shows músico-teatrales", como ellos mismos lo llaman. "Mucho metal, mucha música, mucha diversión. Cinco jóvenes músicos rompen las fronteras de los géneros musicales, llevan el blues a la ópera y J.S. Bach a los caminos de Michoacán... Tocan todo lo que les gusta sin importar los géneros, música barroca o contemporánea, ópera, blues, comedia musical, de cine y folklórica [sic] de todo el mundo [...]". En su página de Internet se pueden encontrar vídeos, audio, así como más datos y fechas de conciertos.

Los ejemplos de fórmulas para estar vigente en el ambiente musical abundan. Podemos citar la agrupación Les Luthiers, el ensamble Louis Berger de música barroca latinoamericana, versiones novedosas como las que ofrecen Il Giardino Armónico, Nigel Kenedy, Sting y, en México, músicos como Horacio Franco, sin contar performances, instalaciones, cortometrajes, en los que se involucra la música y por ende a los músicos.

La preparación académica que se recibe normalmente en las instituciones dedicadas a la enseñanza musical, en ocasiones no es suficiente. Las instituciones llamadas "conservatorio" hacen mucho honor a su nombre, ya que conservan tradiciones y modelos educativos que pueden resultar anacrónicos en el mundo contemporáneo. Sería prudente replantear el concepto, puesto que se está perdiendo su vigencia.

$\mathrm{Al}$ abordar el repertorio de música nueva (creado alrededor de los últimos treinta años), se involucran innovadores recursos y técnicas

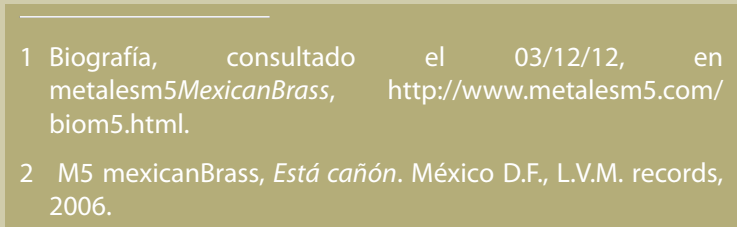


que son habituales en la música contemporánea, mismos que se aprenden a veces hasta de manera anecdótica. Igualmente, surge la necesidad de utilizar software para realizar grabaciones, fotografías y vídeo, y de realizar alguna vez cálculos fiscales, como el IETU, IVA, ISR, así como el llenado correspondiente de dichas formas, lo cual se aprende, por lo general, a manera de ensayo y error.

Muchos de los aspectos que se han hablado pertenecen a otros rubros, y pueden ser aprendidos en seminarios, cursos, como especialidad o maestría, y además existen expertos para hacer cada actividad. $\mathrm{Al}$ alumno rara vez se le informa que se enfrentará a problemas de ese tipo en la vida laboral, y considero que se le pueden impartir disciplinas donde se le proporcionen las herramientas como parte de los planes de estudio actuales, ya que la carrera musical suele ser bastante larga (de 7 a 10 años).

En México, el músico profesional, en casi todos los casos, es también instructor musical, ya sea en instituciones o de manera particular, y por lo regular tiene un rango muy diverso de alumnos (niños, adultos aficionados, estudiantes de música, etcétera), pero en muchos de los casos no sabe enfrentarse a esa situación de manera eficiente. A veces quiere aplicar el rigor de una formación profesional a un niño o la visión de un músico académico a uno aficionado, en ambos casos los niveles de exigencia y los procesos de aprendizaje son distintos a los que él experimentó durante su formación. Si bien es cierto que existe la materia de Pedagogía en los planes de estudio, muchas veces está sólo como un aspecto curricular y no se imparte adecuadamente. Es por ello que las instituciones que ofertan la carrera de música deberían ofrecer al alumno, a la par de su preparación musical, herramientas que le permitan un desempeño óptimo y eficiente de acuerdo a la época en que vive para lograr una satisfacción, no solamente en el aspecto económico, sino también en el académico, social y humano. El manejo de software, una aproximación a la música popular-comercial, así como herramientas de administración, contabilidad, marketing, son ejemplos de aspectos que valdría la pena enseñar en instituciones que ofertan esta carrera. De lo contrario, se forman músicos que, si bien no tienen una preparación musical deficiente, sí insuficiente para los requerimientos actuales.

Desde hace ya varias décadas existe la opción de especializarse en determinado estilo musical, de tal manera que no se hace necesario dominar todo, cosa que sería imposible de hacer. Esta especialización no se contrapone con los conocimientos no musicales (software, contabilidad, etcétera), que son necesarios de adquirir, sino que, por el contrario, estos mismos complementan la labor del músico profesional.

El proceso de globalización que estamos viviendo obliga a buscar nuevas estrategias para la formación profesional, pues esto exige que sea multidisciplinaria, moderna y contemporánea y, en este caso, que sea acorde con el entorno en que se vive para que, de esta forma, el músico pueda ejercer su función social de una manera óptima.

\section{Fuente de consulta}

S/A, "Biografía", consultado el 03/12/12, en: metalesm5MexicanBrass, http://www.metalesm5.com/biom5.html. 